BEYOND INDIVIDUAL BEHAVIORS

Individual behaviors and beyond: Toward a multidimensional view of gamer identity

Crystal N. Steltenpohl, University of Southern Indiana

Jordan Reed, DePaul University

Christopher B. Keys, DePaul University 


\begin{abstract}
Aims. "Gamers" have historically been described via consumption habits and other unidimensional definitions such as genres played. Increasingly, researchers understand social identity as situated within multidimensional contexts, including community members' interactions with other members and society at large.

Methods and results. Our qualitative study involving 434 fighting game community members suggests this expanded, more multidimensional view of social identity is a more accurate reflection of how people who play games view their identities. Our findings focused on four themes of gamer identity: (1) behaviors, (2) player motivations, (3) centrality, and (4) negative perceptions.

Conclusion. Our research complements more recent research on gamer identity incorporating individual-level gaming habits or preferences and group-level identities emerging from out-ofgame and/or in-game worlds. In this way, we consider the influence of multiple contexts on individual identity. Understanding the influence of various social contexts can provide better insight into the multidimensional nature of gamer identity.
\end{abstract}

Keywords: stereotypes, fighting game community, gamers, social identity, groups

\title{
Highlights
}

- While gamer identity has historically been defined largely through game consumption, fighting game community members describe several individual- and community-level factors that influence the meaning of the term to them.

- Motivation to play games play a part in one's understanding of the "gamer" identity, mirroring and expanding upon previous research examining why people play video games.

- Multiple contexts, both inside the game world and in interpersonal relationships with other players, were important in determining the meaning of the "gamer" identity. 


\section{Individual behaviors and beyond: Toward a multidimensional view of gamer identity}

Identities are social labels both constructed by us and placed upon us by society. There is a growing effort to understand identity as a reflexive understanding of oneself beyond one or a series of traits assigned to a person (Rutter \& Bryce, 2006). Identity can be imagined as a conscious sense of self (which some social psychologists define as personal identity) and solidarity with a group's ideals and perspectives (which some define as social identity; Zucker, 2004). Social identity theory examines how belonging to social groups influences personal identity (Trepte, 2006). Social identity, then, is “that part of an individual's self-concept which derives from his knowledge of his membership of a social group (or groups) together with the value and emotional significance attached to that membership" (Tajfel, 1978, p. 63). It provides individuals a definition of who they are through understanding the defining characteristics of their identified categories (Hogg, Terry, \& White, 1995).

The "gamer" identity has historically been conceptualized using a self-identity framework, focusing on players' video game consumption and playing habits (De Grove et al., 2015; Rutter \& Bryce, 2006). Shaw (2013) suggests one is not born a "gamer," but becomes one, primarily through video game consumption. There is increasing evidence that this traditional, one-dimensional definition does not tell the whole story, however, as gamers often interact with one another, both online and offline (Entertainment Software Association, 2016; Koch, Pongratz, McCauley, \& Achtenhagen, 2020; Steltenpohl, Reed, \& Keys, 2018), and with friends and family (Wang, Taylor, \& Sun, 2018). Additionally, motivations for playing games are varied (Koch, Pongratz, McCauley, \& Achtenhagen, 2020; Yee, 2006). Previous research suggests having people with whom to share one's identity is important (De Grove et al., 2015; Rutter \& Bryce, 2006; Shaw, 2012b), and that these identity concepts develop and evolve over time (Harper, 2010; Koch, Pongratz, McCauley, \& Achtenhagen, 2020). It is time for researchers to do the hard work of understanding how different, specific gaming communities may conceptualize their identities and how these conceptualizations may change across environments.

How one conceptualizes one's individual identity appears to be inextricably connected to one's social context (Lyons, Schweitzer, Urick, \& Kuron, 2019). People may create identities via shared interests (De Grove et al., 2015) and shared contexts and experiences (Philpin, Merrell, Warring, Hobby, \& Gregory, 2014). They can form identities based on perceived rejection by others (Schmitt, Spears, \& Branscombe, 2003) and/or hate for the same things (Harman \& Jones, 2013). In contrast, people may show indifference to group identities (Fenton, 2007) or reject them outright (Finlay, 2005). Conflicts between one's experiences and prevailing definitions of identity may arise if one does not conform to expectations (Condis, 2015; Ford, Harris, Webb, \& Jones, 1994) or attempts to enter a new environment (Badea, Jetten, Iyer, \& Er-rafiy, 2011). Research on these multidimensional complexities can advance our understanding of identity.

Consistent with Lyons and colleagues (2019), Grooten and Kowert (2015) argue for a broad understanding of gamer identity including gaming habits or preferences, and group identities emerging from physical/out-of-game and virtual/in-game worlds. These multidimensional aspects interact to influence one's identity as a gamer. In Grooten \& Kowert's (2015) model, how gamers inhabit their virtual and physical realities influences how they identify. For example, gamers aware of stereotypes about gamers may "[identify themselves] or a group in contrast to these [stereotypes] or [attribute] the stereotypes to others rather than to [themselves]" (p. 82). The term gamer has historically been associated with white, straight, ablebodied, teenage males who play video games (Shaw, 2010). However, this stereotype has been 
challenged in recent years, giving rise to several controversies (as described in Dockterman, 2014; Richard, 2015; Shaw, 2012a; Shaw, 2012b).

There is no reason to assume any group would uniformly adopt a label. As an example, what it means to be a "feminist" has undergone change and division depending on historical, cultural, political, and social contexts. Whether individuals consider themselves "feminists" is conditional on conception(s) they hold of feminism, their individual values, and societal norms. Someone may identify specifically as a second or third wave feminist, or intentionally weave intersectionality or transnationalism into what it means to be a feminist. Others may espouse values commonly considered feminist, but self-identify as a different label, such as "egalitarian" (Zucker, 2004), or perhaps reject the use of any label. Further, experiences around other aspects of one's identity, such as race or sexuality, may affect how one interfaces with feminism (see Black feminism, e.g., Porter, Green, Daniels, \& Smola, 2020). Similarly, it is reasonable to expect that not all people who play games accept the "gamer" label. More specifically, how one interfaces with the gaming community (e.g., through specific communities, like the fighting game community) and one's experiences inside and outside of these communities may influence one's conceptualization of what it means to be a "gamer" or whether one feels it is an appropriate label to use.

Within the gaming world, one might make a distinction between casual and hardcore game players. Some genres, such as hidden object games, may more easily be placed into the casual subcategory, which is more often associated with female players (Chess, Evans, \& Baines, 2016). Gaming communities may also be segmented into more specific groups, such as communities of players who enjoy particular genres (e.g., shooters, roleplaying games) or franchises (e.g., Mass Effect, Pokémon). For example, O'Connor and colleagues (2015) found World of Warcraft ( WoW ) players expressed social identity at multiple levels: as gamers, as $W o W$ players, and as guild (in-game groups) members.

The fighting game community (FGC) is one such group of the larger gaming world. FGC members play fighting games (e.g., close combat games like Mortal Kombat, Persona 4 Arena) and interact with other players in many ways, including attending in-person gaming nights, participating in online streams, and posting on social media. Because of its historic roots in arcades, which historically had a much lower cost to play than console and PC gaming, the FGC has been noted as including more low-income and people of color than other gaming communities (Bowman, 2014; Kong \& Theodore, 2011; Skolnik \& Conway, 2019). Additionally, FGC members explicitly resist the formation of fighting game esports to avoid the influence of game developers, broadcasters, sponsorships, and money in general on their community (Toms, 2019). Rather than high-profile tournaments centered on spectating top players, most events include opportunities for all attendees to play (Bowman, 2014).

Meta-stereotypes are the usually disparaging stereotypes in-group members believe outgroup members have of in-group members. Given negative stereotypes against gamers and of FGC members more specifically (Steltenpohl, Reed, \& Keys, 2018), it is important to note metastereotypes can negatively affect self-perceptions (Haslam, Oakes, Reynolds, \& Turner, 1999; Torres \& Charles, 2004). Many FGC meta-stereotypes overlap with those about the general gaming community (Steltenpohl, Reed, \& Keys, 2018). Given this overlap, it is entirely possible some FGC members reject the gamer identity label to avoid some of these stereotypes. In other words, there are a variety of ways FGC members may react to the usage of the gamer identity label, and these reactions may be affected by personal and social contexts. 
In short, the fighting game community appears to be a promising focus for studying gamer identity as it is an underdog, diverse community within the world of gaming that may give rise to varied perspectives on gamer identity. As such it is an appropriate community to examine to ascertain whether fighting game community members have a uni- or multi-dimensional view of gamer identity and, if the latter, recognize and peel back some of the multiple layers of gamer identity. Our focal research questions are: How do members of a gaming community (here, the FGC) envision the gamer identity label? Further, how do they envision their relation to the term?

\section{Respondents}

\section{Method}

A total of 434 respondents answered the open-ended survey question, "What does being a gamer mean to you?" Respondents were diverse on several demographic characteristics (Table $1)$. Respondents averaged 24.50 years old $(\mathrm{SD}=5.15$, range $18-41)$ and reported varying levels of time spent on video games in general and on fighting games specifically. Respondents averaged playing video games for 18.93 years $(S D=5.32$, range $0-37)$ and fighting games for 11.27 years $(S D=7.37$, range $0-28)$.

Respondents interacted with their top community in a variety of ways, including inperson gaming nights, streaming, and social media, each of which roughly three quarters of respondents used to interact with their communities. Respondents came from a variety of specific fighting game communities; most popular were communities relating to Street Fighter, Super Smash Bros., Guilty Gear, and Mortal Kombat.

\section{Materials}

Due to concerns about drive-by research expressed by FGC members (e.g., FGCRequiem, 2014), we leaned into a more participatory framework that allowed for FGC members to help shape our research process to explore various aspects of FGC involvement and identity. The first and third authors worked with FGC members to create an original online survey, "2016 Fighting Game Community Online Survey," which can be accessed on the Open Science Framework (Steltenpohl \& Keys, 2017). The question analyzed for this study is, "What does being a gamer mean to you?" Obtaining open-ended responses from many fighting game community respondents enabled us to obtain multiple perspectives on gamer identity without prejudging the nature of those views.

\section{Procedure}

After obtaining IRB approval and support from FGC leaders, we used a broad, convenience sampling strategy by inviting people with experiences with the FGC to participate in the English-based study via postings on social media (e.g., Facebook, Twitter, various FGCrelated subreddits) and on gaming sites like Game Informer (Futter, 2016). Respondents who identified their "top community" as a game that is not a fighting game (e.g., League of Legends) were excluded from the sample.

\section{Analysis}

The first author created a codebook using open coding and data reduction, paired with iterative practices as themes emerged that aligned with previous research (Srivastava \& Hopwood, 2009). Codes were created if they were mentioned three or more times within the 434 responses; codes were then discussed as a lab, where merging and demarcation occurred through 
discussion and consensus building. In line with consensual qualitative research approaches, the second author independently examined the data and checked his own understanding against the codebook (Hill, Thompson, \& Williams, 1997; Williams \& Morrow, 2009). The first and second authors met to discuss codes until consensus was reached, with the third author acting as an outside auditor. The full codebook is accessible on the Open Science Framework (Steltenpohl, Reed, \& Keys, 2017). In line with our positionality as researchers, described below, the intent of our thematic analysis strategy was to describe participants' experiences, rather than attempt to interpret (and possibly overinterpret) meaning.

Further, to enhance the accuracy, constituent validity (Keys \& Frank, 1987), and credibility of the analysis, we took the following steps. FGC members were invited to participate in member checks three times throughout the process. When designing the survey, we asked several FGC members to provide feedback on question wording and relevance to community needs. We also sought members' comments on initial results of the coding process. Finally, we shared a manuscript draft with FGC members for their reactions. Members reported their perspectives and/or those of their acquaintances were represented and asked questions to clarify specific terms and concepts. To aid with comprehension of the findings, we have included the participant's self-reported age, gender, location, and years within the FGC.

\section{Researcher Positionality}

The three authors have varying levels of engagement with different gaming communities. The first author has been playing video games since she was four years old, has been involved with gaming-related forums since 2003, and has written for a few gaming websites. The second author plays a variety of video games and has been active on several gaming-related subreddits; and the final author has had experience gaming with family members. While none of the authors identify as FGC members, the first two authors attended an anime fighting game tournament and the first author has personal and professional contacts within the community and attends local FGC-related events. All three authors believe communities should be provided an opportunity to speak for themselves and have made concerted efforts not to overinterpret qualitative responses. The authors' positionality helped them establish working relationships and build trust with FGC members in the wake of difficult problems with previous researchers the community had encountered. Consequently, we believe the data from an open-ended survey question was likely to convey community members perspectives in an open and authentic manner.

\section{Results}

A total of four themes emerged from our data analyses. Our first research question concerned how FGC members envisioned the gamer identity label. To this end, two definitional themes emerged: (1) behaviors, i.e., activities relating to being a gamer; and (2) player motivations, adapted from Yee's (2006) motivations for play in online games. Our second research question concerned how FGC members envision their relation to the term gamer. Two conceptual themes emerged: (3) centrality, or how important the gamer label was to them; and (4) negative perceptions, focusing on stereotypes about gamers. Affective statements were found across all four themes, suggesting emotional reactions - positive and negative - to the "gamer" identity label. 


\section{Definition via behaviors}

At the heart of the gamer identity label is a specific activity: gaming. Therefore, a large portion of descriptions of the gamer identity label focused on two behaviors: playing the games themselves, and consuming and creating games and game-related products (e.g., art, streams, etc.; De Grove et al., 2015; Harper, 2010; Rutter \& Bryce, 2006; Shaw, 2013).

\section{Playing games}

Respondents expressed a variety of opinions about which types of games "counted" toward being identified as a gamer. Most respondents either expressly stated it did not matter which games someone played or did not mention playing specific games or genres as antecedents to claiming the identity. One respondent went as far to say, "It means I play video games the fuck you mean?" (23, male, US, 3 years in FGC). Others did not respond as strongly, although shared a similar sentiment: "Someone who plays games. Period. Like many gamers, I feel the instinct to consider mobile gaming less 'valid' than PC and console games, but ultimately it's a True Scotsman argument to claim anyone who plays games 'doesn't count'" (25, male, US, 18 years in FGC). While this respondent resisted his instinct to consider mobile gaming as less valid than other games, a couple respondents did make the distinction. One respondent noted, "A gamer IS NOT someone who plays Clash of Clans [a popular mobile game] on the toilet or while waiting for something else to happen" (19, male, Australia, 3 years in FGC).

In addition to anti-mobile gaming sentiment, a few other distinctions emerged in respondents' reactions, although to a much lesser extent than those who felt it did not matter what genres or games were played. A few respondents insisted gamers were also required to have an appreciation for multiple genres or games, i.e., positive affect and gaming behavior, although it did not appear to matter which genres or games. One respondent stated a gamer is "someone who enjoys and actively plays (or at least tries to, depending on time availability) a variety of video games" (29, male, US, 10 years in FGC). Another suggested gamers should "just enjoy playing games and give every genre a chance" (22, male, US, 6 years in FGC).

Lastly, a few respondents made the distinction between casual and competitive, hardcore, and/or fighting gamers. One respondent described gamers as simply "playing more than just 'casual' games" (33, male, US, 23 years in FGC), while another expanded upon this idea, stating, "To me there is a huge difference between gamers and 'competitive gamer.' Video games are fun, but for me, the challenge of playing against another conscious human being, in which you both want to win, and are forced to try to find a way to beat the other person while at the same time adapting to different situations is much more rewarding than say, trying to defeat a boss so that you can get to the next level. The satisfaction I get from playing at a high level against another person and having a long, thought provoking match, is something that I've yet to find in any other game that's not a fighter" (21, male, US, 10 years in FGC).

\section{Consumption and creation}

Many respondents discussed the consumption and creation of game-related products through buying games and creating and consuming art, streams, and games. A few respondents specifically listed buying games or investing money as an aspect of being a gamer, although not all were happy with this. Some identified gaming identity as a consumerist/capitalist label, with one respondent warning people against using games as an identity. A few other respondents mentioned creating or consuming gaming-related products like art, news, streams, and videos, 
whether in addition to or instead of playing the games themselves. As one respondent put it, "I work in game development and I'm a competitive gamer" (24, trans woman, US, 16 years in FGC).

\section{Definition via player motivations}

As we coded, clear themes echoing Yee's (2006) three motivations of online play emerged: social, achievement, and immersive motivations.

\section{Social}

Those who referenced social aspects of the gamer label focused on three types of social interactions: community, culture, and mentorship. Most respondents who focused on community sought to bond with other players and share their love for their favorite games or genres. As one player put it, aside from playing video games, being a gamer means "being engaged with the people that play the best games in the world" (no demographic information provided).

A few respondents who discussed social aspects of being a gamer referenced having familiarity with gaming culture, whether that involves knowledge of the history, inside jokes, memes of the community, or understanding game design and techniques. One respondent explained, "Being a gamer means understanding the culture, design sensibilities, and appeal of games while being able to discuss them at some level" (no demographic information provided).

A few also listed mentorship as an important part of being a gamer. For example, one respondent said,

"Being a gamer is about the experiences you get when playing games by yourself and with others. Teaching and learning from others is such a rewarding experience that you can't get everywhere. Video games are so commonplace and universal that almost anyone can play and enjoy" (27, male, US, 3 years in FGC).

\section{Achievement}

Roughly the same number of respondents who mentioned the social aspects of being a gamer mentioned aspects of being a gamer relating to achievement, namely competition, improvement, knowledge, and skill. Of these themes, respondents largely focused on competition and improvement, unsurprising for a gaming community revolving around competing in tournaments. One respondent playfully said being a gamer "means expressing [one's] inner smugness in the form of beating others" (21, male, US, 5 years in FGC). Competition was often - but not always - intertwined with improving oneself. As one respondent put it, "I love to improve and compete" (30, male, Sweden, 18 years in FGC). Those who mentioned improvement focused on challenging oneself to get better at the game(s) they enjoyed. As one respondent put it, it is important for gamers to "[rise] to a challenge and [continue] to work on it and improve oneself until the challenge is surmounted" (22, male, US, many years in FGC).

To a much lesser extent, respondents mentioned having attained knowledge or skill, without reference to the process of improving either. Regarding knowledge, respondents mentioned understanding game strategy and how the games are made. As one respondent shared with us, being a gamer means "discuss[ing] the finer points of individual games [...] from an experienced and veteran perspective" (19, male, Canada, 2 years in FGC). Regarding skill, respondents mentioned earning achievements or trophies (an expression and consequence of 
skill). As one respondent put it, "You are a gamer when gaming becomes almost second nature" $(19$, male, US, 9 years in FGC).

\section{Immersion}

Most respondents who discussed immersion as an aspect of being a gamer referenced games being fun, with a few others mentioning immersion within the games or escape from real life responsibilities. Those discussing fun highlighted the importance of enjoying oneself while playing games or enjoying gaming-related products, whether by oneself or with others. Those mentioning immersion discussed a desire to get lost in storylines, explore the game world, or experience the game itself. Finally, many of those who mentioned escape referenced having stressful lives and expressed a desire to relax and/or distract oneself from their responsibilities. As one respondent rather dramatically put it, "to escape the damning reality of crushing defeat is always more fun if you can't ever completely die" (no demographic information provided).

The above findings highlight the variety of ways in which fighting game community members might conceptualize the "gamer" identity. FGC members discussed behaviors, including playing games and consuming and creating games and game-related content, and discussed motivations for playing games as a part of the meaning of the term. When considering how FGC members envision their relationship to the term, two more themes emerged.

\section{Conceptualization via centrality}

The centrality of gamer identity varied across respondents. Most did not reference how important the identity label was to them, but of those that did, there was a roughly equal split between respondents who embraced the gamer identity label and those that did not.

\section{Central}

Some respondents described the gamer identity label and gaming itself as one of the most important aspects of their lives, with gaming taking priority over other activities. For these respondents, gaming was their primary form of entertainment and/or being a gamer was among their primary labels. One respondent shared, "It means video games are not only my most used form of entertainment, but the one that has the most impact on me emotionally and socially" (20, male, US, 5 years in FGC). Another said something similar, putting playing (not making) games on the same level as making art or music:

"It means games take up a large[r] focus of my life then [sic] other hobbies. Just like an artist will spend most of his time making art, a musician making music or a writer writing, a gamer will spend most of his time playing games" (24, male, US, 2 years in FGC).

\section{Important but not central}

Slightly more respondents suggested being a gamer is an important identity but did not specifically reference it as one of the most important. Respondents who reported this second level of centrality noted gaming was a major or influential part of their lives, or they have been gaming for a significant portion of their lives. One stated, "Gamer means that video games are an important and influential part of my life and perspective" (22, male, US, 5 years in FGC). Some, however, specifically asserted that being a gamer is no more important than any other identity category. 


\section{Not important}

About half of respondents who did reference the centrality of the gamer identity label did not care for the term and/or did not use it to describe themselves. Some referenced the growth of gaming as a hobby as a reason for ignoring the label, e.g., "It doesn't mean anything considering the huge amount of people that play video games in some manner" (27, male, US, unknown time in FGC). One pattern of responses indicated playing only fighting games made the broad term less relevant. One respondent said, "I don't consider myself a gamer as I rarely play games when they release except for fighting games" (34, male, US, 24 years in FGC). A few respondents did suggest alternative labels, namely distinguishing between casual and competitive players or identifying as FGC members.

\section{Conceptualization via negative perceptions}

A few respondents shared negative perceptions of the gamer identity. These negative perceptions consisted almost entirely of popular stereotypes of gamers being toxic, exclusionary individuals who take their hobby too seriously. As one respondent said,

"The term 'gamer' has a lot of negative connotations - selfish, socially oblivious, selfimportant, and introverted to a point where there can be a disconnect with the 'real' world. I don't use the term 'gamer' to describe myself. I'm somebody who plays video games very seriously, but I also read books and watch films very seriously. I don't feel the need to shout that out to the world" (24, male, UK, 7 years in FGC).

Most of the respondents who focused on these negative perceptions also stated they distanced themselves from the gamer identity label, although the overlap was not perfect. About two thirds of respondents who distanced themselves from the gamer identity label also mentioned negative stereotypes about gamers.

\section{Discussion}

We were interested in exploring, in broad terms, how members of the FGC conceptualize the gamer identity label and their relation to the term. Their perspectives as members of a specific gaming community are valuable to understanding how the "gamer" identity might be conceptualized differently within these communities when compared to how researchers often conceptualize the term. Our findings focused on four themes: (1) behaviors, (2) player motivations, (3) centrality, and (4) negative perceptions.

As one might expect with an interest-based community, the most salient aspect of community identity did revolve around engagement with the interest. In other words, the consumption of video games was commonly endorsed as a component of gamer identity. Respondents did describe gaming as a primary activity for "gamers," but also mentioned consuming and creating games and game-related products like art and streams. That many respondents seemed to equate game consumption to the creation of other artforms (music, art) is an interesting perspective and further complicates the idea of consumption-based identity; further research is needed to disentangle these concepts.

Respondents also focused on motivations to play, such as being a part of a community and interacting with other players, achievement (e.g., competition, improvement, knowledge, and skill), and immersing oneself in the gaming experience. Respondents differed on how central the term "gamer" was to their identity. Most respondents did not mention centrality specifically, but those who did were roughly split between those who embraced the label and those who did not. 
Finally, a few respondents shared negative perceptions of the gamer identity label, associating the label with stereotypes about gamers generally. Two thirds of these respondents distanced themselves from the gamer term.

Interestingly, despite the focus on a specific gaming community, our results regarding player motivations were congruent with Yee's (2006) three motivations of online play: social, achievement, and immersive motivations. Respondents who emphasized social aspects of gaming discussed community, culture, and mentorship as important parts of their experiences as gamers. Respondents who focused on achievement mentioned competition, improvement, knowledge, and skill, perhaps unsurprising for a competition-focused community. Respondents who drew attention to immersion discussed the importance of fun, with a few desiring immersion within games themselves and escaping from reality. The motivation-related responses were additionally characterized by their affective nature, which suggests emotional attachments and responses are important to consider while trying to understand how someone identifies.

While these motivations may not fit a traditional idea of social identity, they do highlight that gamers inhabit multiple worlds: out-of-game worlds where players interact with others in cooperative and competitive ways, and in-game worlds where players can test their abilities, improve themselves, and lose themselves in the game. These worlds interact with one another to influence one's identity.

This contextual influence aligns with Grooten \& Kowert's (2015) discussion of gamers as a community identity and Harper's (2010) discussion around performing identity. In Grooten \& Kowert's (2015) model, games provide a common ground by which people can connect with one another, creating a culture and shared identity. This shared environment can happen within the game world, through computer-mediated forms of communication like social media and streaming, and through in-person interaction within gaming communities. Within these contextual settings, gamer identity may better be described from a discursive perspective, with the understanding that social identity is socially constructed and intended to lend meaning to experience (Colombo \& Senatore, 2005, Grooten \& Kowert, 2015). The interactions of one's multi-layered social contexts can be positive or negative, as shown by respondents' acknowledgement of positive (e.g., "fun") and negative (e.g., stereotypes of gamers) aspects of being a gamer.

Additionally, different layers of these shared social contexts might be more salient to one's construction of gamer identity. There is research suggesting gamers may more readily identify with specific gaming communities over the general gaming community. For example, some World of Warcraft (a popular Massive Multiplayer Online Roleplaying Game, or MMORPG) players felt a greater sense of community and social identity with other $W o W$ players and specific in-game communities, such as guilds, than the general gaming community (O’Connor, Longman, White, \& Obst, 2015). One can imagine different communities might have different modalities for communication, thus different influences on community members' identities. For instance, the FGC has grown largely from arcade culture (Bowman, 2014), while a massively multiplayer online game like World of Warcraft is often touted as an entirely online game. However, in addition to interacting with each other in person, FGC members talk to each other through social media and in-game voice chat during online play. World of Warcraft players often interact with each other outside of the game environment in online and offline contexts (O’Connor, Longman, White, \& Obst, 2015).

Some respondents in our study noted "everyone games," and suggested the norms for who "gets" to be a gamer might be loosening or shifting, and probably have been for several 
years (De Schutter, 2010; Milner, 2013). That said, there were still respondents who felt to be called a gamer, one should, for example, not play primarily mobile games, or should be wellversed in a variety of games and genres. Still others distinguished between casual and competitive gaming. We would expect the prevalence of the aforementioned perceptions to change depending on what community is being examined, which points to the importance of exploring the perceptions of specific gaming communities, rather than focusing on an increasingly amorphous entity like "gamers." These results are again congruent with Grooten and Kowert's (2015) discussions of gamers as people who self-identify with the gaming community based on perceived shared characteristics with the group. Thus, our findings reinforce and expand upon the idea that a movement away from conceptualizing gamer identity as simply "consuming games" may lead to a better, deeper understanding of what it means to use (or not use) this label.

Even as the "face" of a gamer changes (Entertainment Software Association, 2016), negative stereotypes remain (Dockterman, 2014; Grooten \& Kowert, 2015; Richard, 2015; Shaw, 2012a; Shaw, 2012b; Steltenpohl, Reed, \& Keys, 2018). Respondents who found negative stereotypes salient typically distanced themselves from the label, despite all indications they fit the traditional description of a gamer (that is, they play games), choosing instead to talk about other gamers. This distancing illustrates Grooten and Kowert's (2015) discussion of gamers' differentiation of themselves from stereotypes about gamers.

\section{Implications and Future Research}

As researchers, we seek to be mindful of the labels we use. A proposed best practice for researchers may be to include a question asking how someone may refer to their own social identity. To draw a parallel with Zucker's (2004) study of feminist identity, someone may prefer the label egalitarian rather than feminist, or may identify as feminist but want to specifically say they are a third-wave or an intersectional feminist. Understanding labels people use regarding their social identity helps articulate the complexities of membership and may be useful in gaining entrée into gaming and other communities (Quandt, McDonald, Bell, \& Acury, 1999).

Future research should focus on other specific gaming communities, to explore how identity functions in these communities and what similarities and differences we may find when comparing different groups. Even within the fighting game community, there are several subcommunities, including communities for whom English is not the primary language. There are many avenues, then, for a deeper, more specialized exploration within gaming communities that we hope to explore and encourage other researchers to do as well.

Beyond sampling from other gaming communities, future research on gamer identity could benefit from a more ecological approach, exploring how individuals may feel about their gaming identity in a variety of contexts, how game developers market gamer identity, how society represents gamers and how these have (or have not) changed over time.

Most respondents who provided their gender identity used a masculine label. This finding is in line with previous research suggesting less than 5\% of competitive FGC players are female (Kong \& Theodore, 2011) and research suggesting there are very few women in competitive gaming spaces (Jansz \& Marte, 2005). Our mixed-methods study was, due to a rather limited body of research around the fighting game community, intentionally broad-based, with the purpose of obtaining a variety of perspectives on different, broad topics.

Future research may focus specifically on the ways women and individuals identifying as trans and/or non-binary navigate these spaces. Some researchers have looked at gender and game 
consumption broadly (e.g., Royse, Lee, Undrahbuyan, Hopson, \& Consalvo, 2007), while others have taken deeper dives into how gamer identity is influenced by other characteristics like gender, race, and sexuality (Shaw, 2012a). Previous research suggests gaming communities can be harsh environments for women (Cote, 2017; Fox \& Tang, 2014; Fox \& Tang, 2016). Discussions about gender-based harassment in online gaming space show members often focus on the "authenticity" of membership (i.e., whether women are "real gamers"), a dismissal of potentially sexist behaviors (instead describing them as acceptable for everyone in these communities), and a tentative acceptance of gender as a component of gender-based harassment (Nic Giolla Easpaig, 2018). Kaye and Pennington (2018) suggest using social identity theory to differentiate in-group and out-group categorization and multiple social identities theory to soften the effects of discrimination against women-identified players. For example, social identity theory might suggest it would be helpful for gaming communities to broaden their notion of who "counts" as a "gamer" to reduce the application of gender-based stereotypes. Multiple social identities theory would suggest that female-identified gamers might highlight their gamer identity over their female identity to avoid the application of gender-based stereotypes.

Research further suggests a link between identity and wellbeing (Kaye, Carlisle, \& Griffiths, 2017). Therefore, it would be beneficial to research the link between gaming identity and wellbeing, particularly around the usefulness of gaming community-focused interventions. Understanding the relationship between identity and wellbeing will allow us to understand how members who are in the minority in online and/or gaming spaces identify within these communities and the effects that has on health and social outcomes. It may also help us develop interventions that can improve the wellbeing of people of all backgrounds who play games.

The multidimensional findings of this FGC-specific study are in line with Grooten and Kowert's (2015) conceptualization of gamer identity, which integrates individual gaming habits and preferences with group identities emerging from physical and virtual worlds across gamers in general. They also reflect Yee's (2006) previous research on gaming motivations among MMO players and make more explicit specific ways gamer identity is influenced by social and affective factors. Moreover, like Grooten and Kowert (2015), they extend research conceptualizing social identity as related not only to one-dimensional understandings of identity via overall categories or groups or specific behaviors, but potentially by the interactions of one's various social circles (in this case, the fighting game and general gaming communities).

\section{Conclusion}

Our FGC-specific results provide a multi-faceted understanding of gamer identity through various circles of influence, in line with more modern understandings of identity among gamers generally. These factors provide a broad, basic framework for understanding identity, one involving individual- and community-level variables and their interactions, and affective and motivational responses to identity labels. Taken together, these factors call for a more nuanced and complex view of gamer identity that not only includes one's gaming behavior but also other important human dimensions. 


\section{References}

Badea, C., Jetten, J., Iyer, A., \& Er-rafiy, A. (2011). Negotiating dual identities: The impact of group-based rejection on identification and acculturation. European Journal of Social Psychology, 41, 586-595. http://doi.org/10.1002/ejsp.786

Bowman, M. (2014, February 6). Why the fighting game community is color blind. Polygon. http://www.polygon.com/features/2014/2/6/5361004/fighting-game-diversity

Chess, S., Evans, N. J., \& Baines, J. J. (2016). What does a gamer look like? Video games, advertising, and diversity. Television and New Media, 1-21. https://doi.org/10.1177/1527476416643765

Colombo, M., \& Senatore, A. (2005). The discursive construction of community identity. Journal of Community \& Applied Social Psychology, 15, 48-62. https://doi.org/10.1002/casp.809

Condis, M. (2015). No homosexuals in Star Wars? BioWare, gamer identity, and the politics of privilege in a convergence culture. Convergence, 21, 198-212. http://doi.org/10.1177/1354856514527205

Cote, A. C. (2017). “I can defend myself”: Women's strategies for coping with harassment while gaming online. Games and Culture, 12(2), 136-155. https://doi.org/10.1177/1555412015587603

De Grove, F., Courtois, C., \& Van Looy, J. (2015). How to be a gamer! Exploring personal and social indicators of gamer identity. Journal of Computer-Mediated Communication, 20, 346-361. http://doi.org/10.1111/jcc4.12114

De Schutter, B. (2011). Never too old to play: The appeal of digital games to an older audience. Games and Culture, 6(2), 155-170. https://doi.org/10.1177/1555412010364978

Dockterman, E. (2014, October). What is \#GamerGate and why are women being threatened about video games? TIME. https://time.com/3510381/gamergate-faq/

Entertainment Software Association. (2016). 2016 essential facts about the computer and video game industry. http://www.theesa.com/facts/pdfs/ESA_EF_2008.pdf

Fenton, S. (2007). Indifference towards national identity: What young adults think about being English and British. Nations and Nationalism, 13, 321-339. http://doi.org/10.1111/j.14698129.2007.00279.x

FGCRequiem. (2014). Rage quitting: The reaction to Todd Harper's academic work on the FGC. Requiem's Remembrances: Ruminations from Within the FGC. https://requiemsremembrances.wordpress.com/2014/01/05/an-outside-reflection-thereaction-to-todd-harpers-academic-work-on-the-fgc/

Ford, D. Y., Harris, J.J., Webb, K.S., \& Jones, D.L. (1994). Rejection or Confirmation of Racial Identity: A Dilemma for High-Achieving Blacks? The Journal of Educational Thought (JET) / Revue de la Pensée Éducative, 28, 7-33. http://www.jstor.org.ezproxy.depaul.edu/stable/23767540

Fox, J., \& Tang, W. Y. (2014). Sexism in online video games: The role of conformity to masculine norms and social dominance orientation. Computers in Human Behavior, 33, 314-320. https://doi.org/10.1016/j.chb.2013.07.014

Fox, J., \& Tang, W.Y. (2017). Women's experiences with general and sexual harassment in online video games: Rumination, organizational responsiveness, withdrawal, and coping strategies. New Media \& Society, 19(8), 1290-1307. https://doi.org/10.1177/1461444816635778 
Futter, M. (2016, January 19). DePaul University seeks fighting game community members for psychology research. Game Informer.

http://www.gameinformer.com/b/news/archive/2016/01/19/depaul-university-seeksfighting-game-community-members-for-psychology-research.aspx

Grooten, J., \& Kowert, R. (2015). Going beyond the game: Development of gamer identities within societal discourse and virtual spaces. Loading..., 9, 70-87. https://journals.sfu.ca/loading/index.php/loading/article/view/151

Harman, S., \& Jones, B. (2013). Fifty shades of ghey: Snark fandom and the figure of the antifan. Sexualities, 16, 951-968. https://doi.org/10.1177/1363460713508887

Harper, T. L. (2010). The art of war: Fighting games, performativity, and social game play. (Doctoral dissertation).

Haslam, S. A., Oakes, P. J., Reynolds, K. J., \& Turner, J. C. (1999). Social identity salience and the emergence of stereotype consensus. Personality and Social Psychology Bulletin, 25, 809-818. https://doi.org/10.1177/0146167299025007004

Hill, C. E., Thompson, B. J., \& Williams, E. N. (1997). A guide to conducting consensual qualitative research. The Counseling Psychologist, 25, 517-572. https://doi.org/10.1177/0011000097254001

Hogg, M. A., Terry, D. J., \& White, K. M. (1995). A tale of two theories: A critical comparison of identity theory with social identity theory. Social Psychology Quarterly, 58, 255-269. https://doi.org/10.2307/2787127

Jansz, J., \& Martens, L. (2005). Gaming at a LAN event: The social context of playing video games. New Media \& Society, 7(3), 333-355. https://doi.org/10.1177/1461444805052280

Kaye, L., Carlisle, C-R., \& Griffiths, L. RW. (2017). A contextual account of the psychosocial impacts of social identity in a sample of digital gamers. Psychology of Popular Media Culture. https://doi.org/10.1037/ppm0000173

Kaye, L., \& Pennington, C. (2018). Moving beyond "us" versus "them": Social identities in digital gaming. Psychology of Women's Section Review, 1(2). https://shop.bps.org.uk/psychology-of-women-and-equalities-review-vol-12-winter-2018

Keys, C., \& Frank, S. (1987). Community psychology and the study of organizations. A reciprocal relationship. American Journal of Community Psychology, 15, 239-251.

Koch, N., Pongratz, S., McCauley, B., \& Achtenhagen, L. (2020). 'Smashing it': How user entrepreneurs drive innovation in esports communities. International Journal of Esports, 1(1). https://www.ijesports.org/article/23/html

Kong, S. D., \& Theodore, M. (2011). Competitive Video Games and Social Capital: New Frontiers of Community Formation. UCLA.

Lyons, S. T., Schweizer, L., Urick, M. J., \& Kuron, L. (2019). A dynamic social-ecological model of generational identity in the workplace. Journal of Intergenerational Relationships, 17(1), 1-24. https://doi.org/10.1080/15350770.2018.1500332

McMillan, D. W., \& Chavis, D. M. (1986). Sense of community: A definition and theory. Journal of Community Psychology, 14, 6-23. https://doi.org/10.1002/15206629(198601)14:1\%3C6::AID-JCOP2290140103\%3E3.0.CO;2-I

Milner, R. M. (2013). Contested convergence and the politics of play on GameTrailers.com. Games and Culture, 8(1), 3-25. https://doi.org/10.1177/1555412013478684

Nic Giolla Easpaig, B. (2018). An exploratory study of sexism in online gaming communities: Mapping contested digital terrain. Community Psychology in Global Perspective, 4(2), 119-135. https://doi.org/10.1285/i24212113v4i2p119 
O'Connor, E. L., Longman, H., White, K. M., \& Obst, P. L. (2015). Sense of community, social identity and social support among players of massively multiplayer online games (MMOGs): A qualitative analysis. Journal of Community \& Applied Social Psychology, 25, 459-473. https://doi.org/10.1002/casp.2224

Philpin, S., Merrell, J., Warring, J., Hobby, D., \& Gregory, V. (2014). Memories, identity and homeliness: The social construction of mealtimes in residential care homes in South Wales. Ageing \& Society, 34, 753-789. https://doi.org/10.1017/S0144686X12001274

Porter, C. J., Green, Q., Daniels, M., \& Smola, M. (2020). Black women's socialization and identity development in college: Advancing Black Feminist thought. Journal of Student Affairs Research and Practice, 57(3), 253-265. https://doi.org/10.1080/19496591.2019.1683021

Quandt, S. A., McDonald, J., Bell, R. A., \& Arcury, T. A. (1999). Aging research in multi-ethnic rural communities: Gaining entrée through community involvement. Journal of CrossCultural Gerontology, 14, 113-130. https://doi.org/10.1023/A:1006625029655

Richard, G. T. (2015). Intersecting vulnerabilities in game culture: The effects of inequities and stereotype threat on player confidence, identification and persistence across gender and race. Proceedings of DiGRA 2015: Diversity of Play: Games - Cultures - Identities, (September), 1-5.

Royse, P., Lee, J., Undrahbuyan, B., Hopson, M., \& Consalvo, M. (2007). Women and games: Technologies of the gendered self. New Media \& Society, 9(4), 555-576. https://doi.org/10.1177/1461444807080322

Rutter, J., \& Bryce, J. (2006). Understanding digital games. London: SAGE Publications.

Schmitt, M. T., Spears, R., \& Branscombe, N. R. (2003). Constructing a minority group identity out of shared rejection: The case of international students. European Journal of Social Psychology, 33, 1-12. http://doi.org/10.1002/ejsp.131

Shaw, A. (2010). Identity, identification, and media representation in video game play: An audience reception study, 353. http://doi.org/10.1177/1555412009360414

Shaw, A. (2012a). Do you identify as a gamer? Gender, race, sexuality, and gamer identity. New Media \& Society, 14, 28-44. http://doi.org/10.1177/1461444811410394

Shaw, A. (2012b). Talking to gaymers: Questioning identity, community and media representation. Westminster Papers in Communication \& Culture, 9, 67-89. https://citeseerx.ist.psu.edu/viewdoc/download?doi=10.1.1.692.6712\&rep=rep1\&type $=$ pdf

Shaw, A. (2013). On not becoming gamers: Moving beyond the constructed audience. Ada: A Journal of Gender, New Media, and Technology, 1, 1-24. http://doi.org/10.7264/N33N21B3

Skolnik, M. R., \& Conway, S. (2019). Tusslers, beatdowns, and brothers: A sociohistorical overview of video game arcades and the Street Fighter community. Games and Culture, 14(7-8), 742-762. https://doi.org/10.1177/1555412017727687

Srivastava, P., \& Hopwood, N. (2009). A practical iterative framework for qualitative data analysis. International Journal of Qualitative Methods, 8, 76-84. http://dx.doi.org/10.1177/160940690900800107

Steltenpohl, C.N., \& Keys, C.B. (2017). Fighting Game Study. http://osf.io/qtmwn

Steltenpohl, C.N., Reed, J., \& Keys, C.B. (2017). Codebooks. http://osf.io/bmqvs

Steltenpohl, C.N., Reed, J., \& Keys, C.B. (2018). Do others understand us? Fighting game community member perceptions of others' views of the FGC. Global Journal of Community Psychology Practice, 9, 1-21. https://www.gjcpp.org/en/article.php?issue=28\&article=177 


\section{BEYOND INDIVIDUAL BEHAVIORS}

Toms, C. (2019, May 14). The Growth of the FGC - Watering the Grassroots. Esports Insider. esportsinsider.com/2019/05/the-growth-of-the-fgc-watering-the-grassroots/

Torres, K. C., \& Charles, C. Z. (2004). Metastereotypes and the black-white divide: A qualitative view of race on an elite college campus. Du Bois Review, 1, 115-149. https://doi.org/10.1017/S1742058X0404007X

Trepte S. (2006). Social identity theory. In J. Bryant \& P. Vorderer (Eds.), Psychology of Entertainment (pp. 255-271). Mahwah, NJ: Erlbaum.

Wang, B., Taylor, L., \& Sun, Q. (2018). Families that play together stay together: Investigating family bonding through video games. New Media \& Society, 20(11), 4074-4094. https://doi.org/10.1177/1461444818767667

Williams, E. N., \& Morrow, S. L. (2009). Achieving trustworthiness in qualitative research: A pan-paradigmatic perspective. Psychotherapy Research, 19(4-5), 576-582. https://doi.org/10.1080/10503300802702113

Yee, N. (2006). Motivations for play in online games. CyberPsychology \& Behavior, 9, 772-775. https://doi.org/10.1089/cpb.2006.9.772

Zucker, A. N. (2004) Disavowing social identities: What it means when women say, "I'm not a feminist, but..." Psychology of Women Quarterly, 28(4), 423-435. https://doi.org/10.1111/j.1471-6402.2004.00159.x 
Table 1. Demographic Information on FGC Members

\begin{tabular}{|c|c|}
\hline Characteristic & $\mathrm{N}(\%)$ \\
\hline \multicolumn{2}{|l|}{ Race/Ethnicity } \\
\hline White/Caucasian & $187(43.09)$ \\
\hline Black/African (American) & $21(4.84)$ \\
\hline Asian & $31(7.14)$ \\
\hline Middle Eastern & $3(0.69)$ \\
\hline Latinx/Hispanic & $37(8.53)$ \\
\hline Multiracial/ethnic & $42(9.68)$ \\
\hline Decline to answer & $113(26.04)$ \\
\hline \multicolumn{2}{|l|}{ Gender Identity } \\
\hline Male & $308(70.97)$ \\
\hline Female & $14(3.23)$ \\
\hline Trans/Non-Binary ${ }^{1}$ & $3(0.69)$ \\
\hline Decline to answer & $109(25.12)$ \\
\hline \multicolumn{2}{|l|}{ Sexual Orientation } \\
\hline Heterosexual & $261(60.14)$ \\
\hline Lesbian/Gay & $12(2.76)$ \\
\hline Bi-/Pansexual & $38(8.76)$ \\
\hline Asexual & $3(0.69)$ \\
\hline Sexually fluid/Queer & $1(0.23)$ \\
\hline Decline to answer ${ }^{2}$ & $119(27.42)$ \\
\hline \multicolumn{2}{|l|}{ Disability Status } \\
\hline $\mathrm{Yes}^{3}$ & $33(7.60)$ \\
\hline No & $291(67.05)$ \\
\hline Decline to answer & $110(25.35)$ \\
\hline \multicolumn{2}{|l|}{ Education status } \\
\hline No schooling completed & $1(0.23)$ \\
\hline Kindergarten/nursery school to 8 th grade & $1(0.23)$ \\
\hline Some high school, no diploma & $12(2.76)$ \\
\hline High school graduate, diploma or equivalent & $51(11.75)$ \\
\hline Some college credit, no degree & $109(25.12)$ \\
\hline Trade/technical/vocational training & $12(2.76)$ \\
\hline Associate degree & $27(6.22)$ \\
\hline Bachelor's degree & $91(20.97)$ \\
\hline Master's degree & $17(3.92)$ \\
\hline Professional degree & $3(0.69)$ \\
\hline Doctorate degree & $2(0.46)$ \\
\hline Declined to answer & $108(24.88)$ \\
\hline \multicolumn{2}{|l|}{ Location } \\
\hline North America & $293(67.51)$ \\
\hline South America & $1(0.23)$ \\
\hline Asia & $3(0.69)$ \\
\hline Africa & $1(0.23)$ \\
\hline Europe $^{4}$ & $25(5.76)$ \\
\hline Oceania & $5(1.15)$ \\
\hline
\end{tabular}


Declined to answer

$106(24.42)$

${ }^{1}$ Numbers on trans identity may be underrepresented; we did not specifically ask respondents if they identify as trans.

${ }^{2}$ If a respondent answered in a manner where it was not possible to determine their sexuality (e.g., "male" may be interpreted as "I am interested in males" or "I identify as male"), we placed them in the Decline to answer category.

${ }^{3}$ Of those who provided information on their disability status, the most common responses were ADD/ADHD, anxiety, depression, and Asperger's, while the most common physical disabilities were hearing and visual impairments.

${ }^{4}$ We included Russia as a European country. 


\section{Acknowledgements}

The authors would like to acknowledge Joshua Moore, Mark Belcher, and Robert Hubbs for giving feedback on the survey and for sharing the survey on social media. We also thank DieHard GameFAN, Evansville Esports, Game Informer, and others for publicizing the survey. Thank you to the Online Technologies Lab for continued help with the project. Lastly, we thank various FGC members on Reddit and elsewhere on social media for providing ongoing feedback on our data analyses and interpretation of results.

\section{Funding}

This work was not supported by any external funding bodies.

\section{Author Disclosure Statement}

The authors confirm that there are no conflicts of interest to declare.

\section{Open Access Agreements}

The authors agree to publishing this manuscript using a CC-BY license, if accepted. 